\title{
On the Problems of Just Sentencing in China
}

\author{
BY GuI HuANG*
}

\begin{abstract}
According to the legal norms in China, judges are not allowed to deviate from the sentencing model of deductive legal reasoning and syllogism, and thus, they cannot make law. The inherent limitations of this model figure in the reasoning of judges, such as the poor interpretation of the abstract terms of laws and regulations, the difficulties of identifying legally relevant facts and the simplicity of the reasoning process, which lacks legal rationality. While they are subject to the conditions of the legal system, some external and internal factors influence the judges' reasoning behind their decisions concerning the determination of sentences. The internal factors include the knowledge, judicial experience, special experiences, and attitude of the judge; the external factors refer to the circumstances of the victim, the personality of the offender, the intervention of external power, and the opinion of the public. All of these factors are parts of the dilemma of sentencing justly. Only if the formal and substantive levels of justice are compatible with each other can the justice of sentencing be realized. Finally, this paper would like to put forward some suggestions to deal with the dilemma of sentencing justly, such as improving the quality of sentencing system, standardizing the judges' sentencing skills, improving the criteria of the judges' appointment, and constructing an effective communication channel between the judges and society.
\end{abstract}

Keywords: reasoning of sentencing, judicial justice, limits of deductive reasoning

\section{INTRODUCTION}

Criminal law and criminal norms affect citizens' life and freedom in the most forceful way. By creating criminal norms the state imposes the most severe and rigorous sanctions on citizens. Imposing criminal sanctions (imprisonment, forfeiture, etc.) by which the state constrains its citizens' freedom or takes their property always has to be justified. In modern constitutional democracies criminal procedure and criminal legislation are required to be subject to constitutional principles and they only can function within the framework of human rights. In the European legal culture the European Convention of Human Rights declares: "No one shall be subjected to torture or to inhuman or degrading treatment or punishment" 1 and "No one shall be held guilty of any criminal offence on account of any act or omission which did not constitute a criminal offence under national or international law at the time when it was committed. Nor shall a heavier penalty be imposed than the one that was applicable at the time the criminal offence was committed." ${ }^{2}$ The fundamental principles of criminal justice - e.g. legality, nullum crimen and nulla poena sine lege, proportionality of punishments, etc. - are the most important legal guarantees against arbitrary power of the state. These principles demand accessibility, predictability and legal certainty in criminal legal practice.

1 Article 3 of the European Convention on Human Rights (Prohibition of Torture).

2 Article 7 of the European Convention on Human Rights (No Punishment without Law).

* PhD student, Department of Criminal Law and Criminology, Faculty of Law, University of Debrecen. E-mail: hg_0125@126.com 
The fundamental principles of criminal law do not apply only to the legislator enacting criminal statutes but also to judges when they decide criminal cases. Judges are required to justify their decisions in every case. This requirement includes highlighting the relevant legal and factual basis of the decisions and throwing light on the arguments that led the judge to inflict a particular punishment on an offender. Although judges - when interpreting criminal statutes - are required to adhere to the text of criminal norms ${ }^{3}$ and they are bound by the law, they have a relatively broad discretionary power when deciding the proper amount of punishment. This does not entail the possibility that judges have the power to determine any type and amount of punishment in a particular case. Punishments should be proportional to the harm caused by the criminal conduct and to the level of culpability that characterized the offender's mind when s/he committed the crime. Judges have to be able to justify their decisions regarding the sentences they determine as the right legal answer to criminal conduct. ${ }^{4}$ In this paper I will concentrate on the problem of justifying judicial decisions concerning the infliction of penalties on offenders. My analysis will focus on the problems of justifying sentences imposed by criminal judges in Chinese judicial practice. I contend that these problems relating to justification undermine the rightfulness of the decisions.

In China, the justice of sentencing decisions has always been questioned by the whole of society in recent years. One notable feature of unjust sentencing in judicial practice is the inconsistency in the results of sentences, namely, different judges determine different penalties for crimes that have been committed under similar circumstances. ${ }^{5}$ Because of this very serious problem of injustice, the judicial authorities in China, for the sake of ensuring impartial sentencing, have embarked upon a bottom-up judicial reform of the practice of sentencing. However, the problems of how to promote the judicial reform of sentencing in China, and which conception of justice - the formal or the substantial conception of justice or both of them - the judicial reform wishes to pursue have always been debated by theorists and practitioners.

Based on the above mentioned problems and in order to analyze the problems of sentencing justly in China, this paper plans to explore the limitations of reasoning behind particular sentences and to study the external and internal factors which affect the justification of sentences determined by judges. After that, this paper will take the conceptions of justice into consideration. Finally, I will attempt to find the solutions that are able to guarantee that judges will sentence justly under the guidance of the conception of justice, which should be pursued by the judicial reform in China.

3 For instance, it is not allowed in criminal law to apply analogies or to convict and punish a person for a conduct which cannot be qualified as a crime according to the text of the criminal rules.

4 In 1992 the Council of Europe drafted a recommendation on the consistency of sentencing with the aim of achieving a greater consistency between the sentencing practice of courts in Europe. It contains suggestions concerning the rationales of sentencing, the structure of penalties, aggravating and mitigating factors and so on. This recommendation expects European judges to determine particular punishments according to common European principles which can lead to a coherent and justified sentencing system in the EU. [Council of Europe Committee of Ministers, Recommendation Nr. R (92) 17]

5 As Jerome Frank demonstrated, this kind of inconsistency can arise even within the sentencing practice of judges who work in the same court. Frank (1963) 120. 


\section{THE LIMITATIONS OF DEDUCTIVE REASONING IN SENTENCING}

Although a lot of guiding cases have been issued recently by the Supreme People's Court of the People's Republic of China, they do not serve as the legal basis of sentencing, but only as a reference guide for the judges. The Criminal Code and its judicial interpretations in China, actually, are the primary legal grounds for the judges to justify particular sentences. So the basic model of reasoning behind the infliction of sentences in China is determined by the legal system. This is, and can only be deductive reasoning. In other words, the basic paradigm of the reasoning style in China can be described as the following. Firstly, judges have to find the sentencing rules which can be applied to the individual case from the relevant sentencing laws and regulations, and then they have to interpret them. This will serve as the major premise of reasoning. After this, the judges have to establish the facts of the case, which will serve as the minor premise of reasoning. Finally, they have to deduct the results according to the process of deductive reasoning.

According to the legal culture, China's judges cannot deviate from the model of reasoning used in the determination of sentences. This is the so-called deductive legal reasoning. However, it is inevitable that this model of reasoning has its own inherent limitations in judicial applications of law, and these limitations figure in the reasoning process.

\subsection{Problems of interpreting the abstract terms of sentencing laws and regulations}

The sentencing laws and regulations are the major premise and the vital basis of the reasoning which underlies sentencing decisions in judicial practice. If they are inappropriately interpreted the justice of sentencing results would be significantly violated. The sentencing laws and regulations, which are all formed in a very abstract way, are totally determined by a series of legal concepts and other legal elements. That is why it is a relatively complicated process to interpret legal concepts and apply them to facts. These interpretations depend mostly on the judges' knowledge, experience and their intuition. As Jaques Ghestin and Gilles Goubeaux state "the choice of premises, to a great extent, depends on the judges' intuitions, and it would make the reasoning result become uncertain". 6

During the sentencing process, different interpretations of sentencing laws and regulations differently influence the judges to choose the basic line and level of severity of the penalty. For example, if judges make different interpretations of the concept and extension of "banking institution" in the provision of "robbing a bank or any other banking institution", they will have different choices between the sentencing margin of the fixedterm imprisonment of not less than three years but no more than five years and of the fixedterm imprisonment of not less than ten years but not more than twelve years.

In judicial practice, although there are many judicial interpretations and the Guiding Opinions of the People's Court for Sentencing on Trial [hereinafter: the Sentencing Guide (on trial) $]^{7}$ made by the Supreme People's Court and regional high courts, they cannot make an exhaustive list of the legal concepts and legal elements, and they even have to use more

6 Ghestin and Goubeaux (2004) 38.

7 The Office of Judicial Reform of the Supreme People's Court of PRC, 'The Guiding Opinions of the People's Court for Sentencing on Trial' (Special Report, 18 September 2010) <http://www. chinacourt.org/article/detail/2013/04/id/948052.shtml> accessed 14 November 2014. 
obscure concepts to make clear the original concepts. ${ }^{8}$ For instance, the term "general" in the sentence "circumstances of crime and its results are general" makes difficult for a judge to give it a clear meaning., So, it is becoming increasingly important whether or not the connotation and denotation of the concept are able to contain the legally relevant facts of sentencing in an individual case.

Even if these legal concepts and elements, as well as the useless, obscure and abstruse components were excluded judges still have to use a set of special professional vocabularies to interpret the laws and regulations. If they use everyday expressions, these expressions have to be given a correct meaning. However, this may not always be possible. So in interpreting statutes, the supplementary and benefit equilibrium of the legal provisions and extra judicial factors are very important impact factors and grounds which influence the judge to interpret the sentencing provisions which serve as the major premise.

These factors and grounds usually also lead different judges to give different interpretations. The consequence of this is that the sentencing results will be different as well. Sometimes judges inflict an abnormally lenient or abnormally severe punishment on the offenders. According to the analysis of some complex cases, there are still relatively many cases in which sentencing results differ from each other due to the different interpretation of sentencing laws and regulations. This is the main reason for the public to question the justice of the sentencing result.

\subsection{Difficulties in identifying the legally relevant facts}

The facts related to the sentencing in an individual case, which serve as the minor premise of reasoning, cannot be solely described by using ordinary vocabulary. When ordinary terms are used to describe the facts of the case they have to get special legal characteristics. It, thus, is far more important to identify the legally relevant facts which are related to the sentencing decision. The concepts and elements of the sentencing laws and regulations are specified and listed exhaustively by judicial practice and the sentencing guidance. But, the actual facts, which are related to the case, are not always consistent with legal concepts and provisions, so there have been always discussions about whether or not to apply the legal concepts to the facts of the case.

For example, in a robbery case, the fact that an offender broke into a property which served both as a place of residence and the site of a business operation can cause difficulties in interpretation. The question is whether the offender could be convicted according to the provision "intruding into another person's residence to rob" provided by the Article 263 of Criminal Law of $P R C^{9}$.

Concerning this, some people believe that the fact that the offender broke into a house at "business time" could be covered by the meaning of the concept of "housebreaking", namely the offender having intruded into another person's residence to rob. But some people think that the right interpretation could depend on the time: when the offender stepped into the property during the period of business, this should have been qualified as a public place, and thus it could not be interpreted as "housebreaking." However, they say, if the offender entered the place and robbed outside of business hours, he or she could be convicted as a person who "has intruded into another person's residence to rob". Thus, due

8 About the relevancy and efficiency of a sentencing guideline in judicial sentencing practice see Stith and Cabranes (1998) 104-142.

9 Criminal Law of People’s Republic of China 1997, Article 263. 
to the legal terminology and its expression, it is extremely difficult to identify the legal facts in judicial practice. This leads to a very incoherent sentencing system in judicial practice.

\subsection{Problems of deductive reasoning}

Deductive reasoning is a process by which the judge deduces a conclusion from a certain major premise and a minor premise. In a legal system which is based mostly on the legislated law legal decisions are inferred from the laws and regulations which serve as the major premise, and the legally relevant facts which serve as the minor premise. So in the process of deductive reasoning the judges have to interpret the abstract legal concepts, meanwhile summarizing and extracting the specific facts related to sentencing, and then deciding whether or not these facts can be contained by the sentencing provisions. If the sentencing provision can be applied the judge can make further deductions. Subjected to the inherent constraints of the positive law judges cannot make law when they apply the laws and regulations of sentencing, however, it is possible for them to cite the corresponding judicial interpretations.

The judges evaluate the effects of the crime on society according to their personal intuition and then make a sentencing decision. Meanwhile, due to the highly recapitulated nature of the legal language, the procedures of summarizing and extracting legally relevant facts become simple, lacking legal reasoning and rigorous logical procedure. For these defects, according to the conclusion of my analysis of cases published by the Supreme Court and regional high courts, in most of the criminal judgments the reasons for the sentencing results and the reasoning procedures are very simple, some of the decisions contain simply a short sentence without any reasoning, and even if judges cite the relevant provision, they particularly declare whether "the social harmfulness is great or not.” This serves as the justification of sentencing decisions, without any explanation of the meaning of social harmfulness and without exploring the responsibility aspects of the crime.

\subsection{Deficiencies of the legal background of sentencing}

As I stated above, the sentencing legal norms serve as the major premise of deductive reasoning and should be interpreted by the judges when they are sentencing. If the sentencing regulations are extremely abstract and they lack any corresponding interpretation or instruction, it would prevent judges from understanding the sentencing regulations. This makes the application of laws and regulations controversial, and finally it would lead to huge differences between the results of sentencing decisions.

In China the reform of sentencing has been brought into effect since 2009 and the Sentencing Guide (on trial) has been issued by the Supreme People's Court, which provides the concrete sentencing steps and the applicable standards of penalty for common crimes. However, it failed to put this reform into practice around the whole country and it has not included all crimes. Furthermore, there are many abstract concepts which contain value judgments, such as "the circumstances of crimes in general" and "the social harmfulness is not so serious”.

To some extent, this gives much more space for the judges to make decisions, but, to a great extent, it also easily leads to the result that judges understand the sentencing laws and regulations in a different way. The result of this practice is that the legal system cannot fulfill its function. 


\section{ANALYSIS OF THE EXTERNAL AND INTERNAL FACTORS THAT HAVE AN INFLUENCE ON THE REASONING OF JUDICIAL DECISIONS IN CHINA}

\subsection{The internal factors influencing the judges' reasoning of sentencing}

The internal factors influencing the reasoning behind the determination of sentences refer to the factors that affect how the judge is interpreting abstract provisions, summarizing and extracting legally relevant facts, and deducing the results of sentencing.

\subsubsection{Personal knowledge as the background of judicial decisions}

The background knowledge of the judge refers to educational attainment, range of knowledge and so on. The background of the judges' knowledge affects the judicial decision by influencing the judges' ability to perceive sentencing provisions, to identify the legally relevant facts in an individual case, and to deduce the sentencing result from the abstract provision, which serve as the major premise, and specific facts, which serve as minor premise.

Beside the legal knowledge, which is the basis of understanding, other kinds of knowledge, such as basic medical knowledge, financial knowledge and so on, could be helpful for judges to understand the laws and regulations and to summarize sentencing facts in an individual case. Generally speaking, the judges who graduate from law school and become highly educated, as they have a scientific training in law and even did some special legal research, can understand the legislative intent and spirit in a more sophisticated way. Such training helps to guarantee that judges will choose and apply abstract laws and regulations correctly.

\subsubsection{The judge's personal experience}

The judicial experience of judges makes it possible for a judge to grasp and understand the legal provisions through the concrete judicial operation, and it is also an important way for the judges to know that the same hypothesis of the sentencing provision has different results in different cases. So it can enable the judges to understand the abstract provisions and to understand that the same crime can be committed in various ways. So it can improve the judges' ability to summarize legally relevant facts in an individual case, so that they can correctly apply the laws and identify the legal facts and then deduce a just sentence.

However, extensive judicial experience does not necessarily enable the judges to infer just sentences from the statutes. One important reason for this is that having a serious attitude towards one's work plays a vital role in adjudication. It is inevitable that the rich judicial experience is in proportion to years of work experience, which means that the longer the working years are, the richer the experience becomes. But it is also able to make judges develop a monotonic attitude towards their work, and thus, drive judges to adopt an indifferent, passive or perfunctory attitude. For instance, when the judge believes him- or herself to have rich judicial experience due to which s/he is able to grasp and understand the laws and regulations and the specific facts in a single case, s/he may be led to think that judicial decision making is simple or that arriving to a particular decision does not require an in-depth analysis. This attitude would easily result in unjust sentencing.

In comparison, the judge who has less experience in judicial practice and believes that $\mathrm{s} / \mathrm{he}$ lacks the ability to identify the laws and regulations and specific facts in an individual case, tends to possess a cautious and serious attitude, and deals with the case in a most careful manner. Thus, to a great extent, this kind of cautious judicial attitude can lead to sentencing decisions strictly in accordance with the law. Some researchers have explored 
this issue, and the result of the survey is that "most of the judges said that the working life had a significant influence on judicial decisions. If the years of judicial work experience are only few, judges are likely to deal with the case mechanically, they decide according to the laws and regulations when they are sentencing; but the judges who have a long time of work, they would give much more consideration to the extra judicial factors, and they do not sentence only according to the laws and regulations, but have to pay close attention to the attitude of the leaders and the public."10

\subsubsection{The judge's special personal experiences}

What do we mean by "special experiences"? For instance, if a judge or his or her family was ever violated by a criminal, or the judge personally saw somebody being violated by a crime, then this could have an impact on judicial decision making. These special experiences, to a great extent, make the judges personally feel some pain because of the crimes and then create resentment against the offender. This attitude provokes the sense of justice of the judges.

Thus, judges are likely to resonate with the pain suffered by the victims. Because of this, their sense of disgust towards the crime and the offender is stimulated, which would make the judges understand and apply the laws and regulations with much more emotion rather than rationality.

Considering the term "social harmfulness", judges who were victims of certain crimes would tend to interpret this concept according to their own experience. However, judges who did not suffer from violation are usually confined to the legal language and decide according to the text of the law. In addition, regarding the summarizing and extracting facts in a single case, judges who have special experiences are more or less influenced by some emotions and thus it leads them to make inappropriate judgments. Due to these attitudes of judges the justice of the result can be violated.

3.1.4. The attitude of judges to the crime itself

The attitude of judges can be influenced by not only the whole crime situation, but also by understanding the cause of the crime, the personality of the criminal and the victim of the specific crime. Generally speaking, when judges believe that the level of crime in their society is exceptionally high and thus needs to be controlled by strict punishment, they are likely to exaggerate the interpretation of social harmfulness of criminal behavior when they ascertain the legally relevant facts related to sentencing, and they are likely to apply more severe punishment when they choose and apply sentencing laws and regulations.

\subsection{The external factors affecting the reasoning of sentences}

The external factors affecting the reasoning of sentencing means the extra judicial factors which are not part of the judges' personality. They have an influence on judges when they apply the abstract sentence provision and identify the sentence factors, and deduce the result of sentencing.

10 Rong (2013) 67 
3.2.1. The attributes of the victim

The attributes of the victim, which have an influence on sentencing, include the background, social status, reasons for suffering a criminal offense and the victim's attitude towards the criminal.

Background and social status usually determines someone's material wealth, literacy and reputation, which to a great extent also determines someone's social attributes, namely, whether he or she is part of a vulnerable group. The members of a vulnerable group are inferior to other people in terms of economic and social status, literacy, etc. In China, most of the time, for this group of people it is difficult to settle the confronting social problems, and they suffer pressure from other groups. All of these would lead them to get into more trouble and worse circumstances.

In criminal cases, usually, victims have already been a member of a vulnerable group and when they are violated by crimes their family is usually involved as well. So this often has an influence on judges when they interpret the social harmfulness of the crime and then it also has an influence on judges when they impose a criminal sanction. In addition, the victim of a vulnerable group could easily receive sympathy from judges, which also would have an influence on judges when they make decisions.

The reasons for suffering a violation do not only urge judges to determine the nature of behavior in a crime, but also influence judges when they identify the facts which are relevant in sentencing. These reasons could include legal factors and non-legal factors as well. For example, in the case of the crime of creating disturbances, if the judge finds out that the victim provoked the offender he will take this into consideration when convicting the defendant; or in the crime of causing traffic casualties the illegal behavior of the victim, which contributed to the traffic casualty, would also influence the judge when s/he engages in balancing the legal facts and makes a decision about the punishment.

However, the reasons for suffering from a crime have both legal factors and non-legal factors. The attitude of the victim to the criminal is also a significant factor that influences the judges when they make decisions about the right punishment. One such example is the case of criminal reconciliation. The Sentencing Guide (on trial) has clearly defined criminal reconciliation as a circumstance for lighter punishment. Furthermore, in judicial practice, criminal reconciliation cannot be taken as an agreement on criminal settlement, but when the crime took place between the relatives and neighbors, if the victim forgives the criminal it would also influence the judge when s/he makes a sentencing decision.

For instance, the case of State $v$ Hao Weidong ${ }^{11}$, in which Hao Weidong stole his uncle's money, the Supreme People's Court of P.R.C. reviewed this case and stated that, "Hao Weidong stole a huge amount of money, but it took place in a close relationship which includes a common background and living circumstances, and the victim, Hao Xihou, intended to forgive his nephew and asked the court not to investigate the criminal responsibility". According to the special situation this case should be identified as "the circumstances of a person's crime are counted as mitigating factors and do not require criminal punishment", which is provided by Article 37. However, the punishment in the original judgment, which sentenced Hao Weidong to a punishment less than the prescribed punishment, is still a heavy punishment."12

11 The Bulletins of the Supreme People’s Court of the People’s Republic of China Vol. 2013 (People’s Court Press 2012).

12 The Bulletins of the Supreme People's Court of the People's Republic of China Vol.2013 (People’s Court Press 2012) 463. 
3.2.2. The attributes of the criminal's personality

One important factor affecting judicial decision making concerning sentences is the factor of the criminal's personality, which includes the criminal's background, social status, duties and habitual behavior. In judicial practice the cases in which the features of the criminal's personality influence judges in adjudication are very common. For example, the cases of Wu Ying ${ }^{13}$ and Gao Xiaosong ${ }^{14}$ were of great concern to the broader community because of their special status and identity, which also inevitably urged the judge to take their situation seriously and deal with these cases more carefully.

The main features of these factors are that they are able to induce public resentment against a particular group, for instance, bribery and corruption can generate public resentment against the corrupt officials; or they could raise public doubts about the judicial justice and bring about public condemnation against the public authorities, for example, in the case of Li Qiming ${ }^{15}$, who caused traffic casualties. Li caused the death of one person and one serious injury with his car when he drove to a campus. His reaction was the following: "my father's name is Li Gang, who is the head of the police." After that, the whole society condemned Li Qiming and his father, but most of the public condemned the public authorities and judicial corruption represented by the statement "My father's name is Li Gang."

Moreover, it can occur that celebrities commit crimes, such as in the case of Gao, who drove under the influence of alcohol, and in the case of Huang, who was one of China's richest persons. The habitual behavior of the defendants can have an influence on judicial decisions concerning sentences. Good habits in daily life, to a great extent, can easily explain the contingency of crime and the possibility of repentance, but the bad daily behavior, to a great extent, can make judges think that the defendant tends to commit crimes easily and is reluctant to show repentance. When judges make discretional decisions on penalties, all of these behavioral attitudes will be taken into consideration by them and these factors will to a great extent have an influence on their decisions.

\subsubsection{The intervention of external power}

The "intervention of external power" refers to other persons or organizations that intervene in adjudication and violate the right to fair trial and judicial independence. In China, these kinds of intervention come mostly from the superior departments of the internal system of the courts or the leaders of courts, or the leaders of organizations of state power or from the government.

The reasons behind interventions of superior departments or leaders are the following: there is a system of "asking instructions from the superior departments" in the internal system of the courts, or presiding judges ask instructions about the special case from the head of the department, or the leaders intervene or are involved in special cases in various forms with certain aims.

The organizations of state power or governments' intervention come mostly from the Political and Legal Committee or from the coordination meeting organized by the Political and Legal Committee. The results of these interventions usually make judges deal with the case in a manner that fits the decisions of the committee and the will of the leadership.

13 State v Wuying [2009]. Zhejin the Second Criminal Court First Trial. No.1 [2010] Zhe the Second Criminal Court Second Trial. No.27.

14 State v Gao Xiaosong [2011]. East Destrict the Second Criminal Court First Trial. No.438.

15 State v Li Qiming [2010]. Hewang Criminal Trial. No. 10. 
Thus, judges are influenced to estimate the social harmfulness of the crime and to ascertain the facts related to sentencing, meanwhile they also influence judges in adjudication of sentences. So the existence of deviation between sentencing results will be inevitable.

\subsubsection{The opinion of the public}

Recently it is a very common phenomenon that public opinion influences the judiciary, particularly in the criminal judicial field. Moreover, the impact of public opinion has grown with even more intensity nowadays, such as in the case of $\mathrm{Xu}_{\mathrm{Ting}}{ }^{16}$, in the case of Yao Jiaxin $^{17}$, and in the case of Li Changkui ${ }^{18}$, which reflect the influence of the public opinions on the criminal practice.

The most important signs of the impact of public opinion on judicial decision making are the case of $\mathrm{Xu}$, in which the judge changed the punishment of life imprisonment to a fixed term of 5 years; the case of Yao, where the public was concerned about the death penalty in the two trials; the case of $\mathrm{Li}$, where the sentencing result changed from death penalty with immediate execution to death penalty with suspension, and then at the retrial procedure the sentence was altered to death penalty with execution. These cases prove that public opinion has played an important role in changing sentencing results.

The fact that public opinion influences judges in adjudication to a great extent expresses the public's dissatisfaction with the criminal justice system, but actually, it shows that it is the laymen who deliver sentences to the criminals in an offensive manner.

There are two ways to form public opinions about criminal decisions: one is the traditional way, such as the television, broadcast and newspapers; another one is the community media, which is the most important channel to express public opinion and is also an important way to influence judicial practice.

Public opinion not only influences judges when they interpret and apply the sentencing laws and regulations, but also influences judges when they evaluate the concept of social harmfulness described by the criminal law, and also affect judges when they ascertain the legally relevant facts. The opinions expressed by the public on criminal judicial practice include both rationality and sensibility. The prime causes of both rational opinions and perceptual opinions are that the public worries and doubts the justice of current criminal judicial practice, and, to a great extent, reflects the gaps between the social justice which the public wants to achieve and the justice of current criminal judicial practice.

\section{VALUES FOSTERED BY JUDGES IN CHINA}

\subsection{The value of desert: guaranteeing the justice of the results of sentencing}

The justice of the results of sentencing decisions can be divided into two levels, namely substantial justice and formal justice. Formal justice can be interpreted in terms of concrete cases. It means that the result of sentencing reflects that the punishment fits the nature of the particular crime and the dangerous character of the criminal's personality in an

16 State v Xuting [2007] Hui Intermediate the Second Criminal Court First Trial. No.196. [2008] Hui Intermediate the Second Criminal Court Second Trial. No.2. [2008] Hui Criminal Court Retrial. No.197.

17 State v Yao Jiaxin [2011] Xi the First Criminal Court First Trial. No.68.

18 State v Li Changkui [2010] Zhao intermediate Criminal Court First Trial. No.52. [2010] Yun high Court Second Trial No.1314. 
individual case. The results also should meet the requirements of substantial rationality and the requirement of justice of the individual case.

The latter conception of justice figures in terms of similar individual cases. It means that a unified standard should be applied to situations and circumstances in similar cases. It also should realize the principle that "the same or similar crimes should be punished in the same or similar way". The two forms of justice, the formal and substantial conceptions, are complementary.

4.2. The actual value in an individual case: guaranteeing the proportionality of the results of sentencing

The uniformity between the results of sentencing means - according to some scholars - that concerning the same crimes and same cases judges should reach the same sentencing decision, and different crimes and different cases should be sentenced differently, moreover, the judicial decisions should be consistent and in continuity with space and time. The requirement that the results of sentencing should be established in a coherent and consistent manner can be inferred from the principle that punishments should be in proportion to particular crimes.

The Criminal Law declares that "the degree of punishment shall be commensurate with the crime committed and the criminal responsibility of the offender." ${ }^{19}$ This article, to some extent, requires the punishment and crime to be commensurable in an individual case which should be realized as the basic requirement of justice in individual cases. And pursuing the relative uniformity between the individual cases, especially between the same or similar cases is now the core task of criminal judicial practice.

In judicial practice, the severity of punishments differs significantly in the same or similar cases. The problems of sentencing incoherently and the significant disparity in making decisions about punishments are the main causes of violating social justice. The aim of balancing the practice of sentencing is to deal with the problem of the severity of punishments differing significantly in the same or similar cases.

\section{THE SOLUTIONS FOR THE DILEMMA OF SENTENCING JUSTLY IN CHINA}

\subsection{Improving the legal background of sentencing}

In China, the legal background of sentencing, now, is comprised by Criminal Law and its judicial interpretations. The Supreme Court issued the Sentencing Guide (on trial), which declares the judicial procedures of sentencing, and offers judges referential data to improve the reasoning of sentencing decisions. It tightens the gaps of sentencing results between decisions, but it still needs further suggestions for real improvement.

Firstly, it should shorten the trial period of the reform of sentencing standardization and it should realize the reform in judicial practice. Secondly, it is important to promulgate a far more detailed Sentencing Guideline and allow the regional high courts to make a far more detailed implementation of rules within the scope of the Sentencing Guide according to the local economic, social and criminal situation, so that it is required to make the Sentencing Guideline fully operational.

19 Criminal Law of People’s Republic of China 1997. Article 5. 
Furthermore, it needs to compile all the provisions of the Sentencing Guideline and its detailed implementation of rules made by regional high courts into a volume so that it can tighten the gaps between sentencing rules and decisions. By creating this compilation it would be possible to decrease the rate of imbalanced sentencing results due to the defects of sentencing laws and regulations. Thirdly, it is necessary to establish a case-guiding system. It is necessary that judges be allowed to cite the cases that are involved in the case-guiding system, and rely on these cases as important reasons and grounds for determining punishments. This system would enable judges to interpret the disputed issues and legal concepts in a far more comprehensive and detailed way. Furthermore, it would foster deducing the results of sentencing in a more coherent manner.

Meanwhile, in order to eliminate the disadvantages of ambiguous terms, judges could be allowed to use the previous cases which can help them understand and interpret presumptions described by legal terms. So, the legal system needs to build a database with previous legal decisions, which could be searched on the internet.

In addition, the legal system also needs to establish an institution which would serve as an authority guiding judicial interpretations. This institution could be responsible for formulating, amending and interpreting the Sentencing Guideline and sentencing policies, and supervise the implementation of the Detailed Implementation Rules of the Sentencing Guideline formulated by the regional high courts. This authority would also have the right to make suggestions for correcting inappropriate sentencing cases.

\subsection{Standardizing judicial skills of establishing sentences}

According to the results of my research and the results of the analysis of the judgments published by regional courts, it has come to light that judicial decisions lack real reasoning when judges state the reasons for their decisions about punishments. It is clear that judicial decisions lack interpretation of sentencing laws and regulations, judges usually cite the sentencing provisions and seldom interpret the legislative intent.

To a great extent, my research proves that judges are not confident in their legal knowledge and the ability to interpret the sentencing laws and regulations, and it also shows that judges do not pay much attention to the reasoning procedure of sentencing.

So the legal system needs to improve judges' ability to interpret sentencing laws and regulations. The interpretative ability can only be improved by teaching and training and by judges learning how to apply their legal knowledge to individual cases. By setting up a special training system judges will learn to avoid resorting only to the literal meaning of statutes and applying regulations in a doctrinaire manner. By interpreting and understanding deeply the legislative spirit and intent judges would be able to apply sentencing laws and regulations accurately.

\subsection{Improving the criteria of judges' appointment}

In the process of justifying sentences judges play a decisive role. The rules and regulations of punishments and legally relevant facts as objective and external factors in the process can only have an effect on judicial reasoning if judges have a subjective consciousness in relation to the results of their decisions on sentences.

The character and justice of the results of sentencing usually depend on conscious activity. During the procedure of reasoning that justifies sentences, one of the most important embodiments of the judges' subjective initiative is their academic preparation, judicial experience, and personal judicial competence, the ability to settle disputes, social 
perception and so on. It requires a relatively long period of time to form and improve all these personal qualities, and they can be improved by rich judicial experience and legal academic preparation, so it is necessary to improve the criteria of the appointment of judges, and the overall quality of judicial skills. This will decrease the possibility of there being an imbalance and variation in sentencing.

\subsection{Constructing an effective communication channel between judges and society}

As was mentioned above, one of the most important external factors affecting judges in sentencing is public opinion. So we have to coordinate the relationship between the courts, who exercise judicial power independently, and the public, who supervise judicial activities. In order to make the criminal judgment acceptable to society without causing extensive concern to public, it is necessary to construct and improve the ways and channels of communication, so that public opinions can be heard by judges.

However, this does not mean that judges have to completely accept public opinions, but only that these opinions can serve as a point of reference. In order to achieve this goal judges should communicate with and reply to the public. In this way the professional rationality of judges and the conceptions of the public could reach a consensus and agree mutually during these communications, and even bridge the gaps of the conceptions of values between judges and the public.

The methods for constructing effective communication channels could be the following: firstly, it is necessary to improve and reform the assessorial system of the people. For instance, a dualistic assessment system should be implemented, namely, a simultaneously existing system of the people's assessors and the people's jury. This means that in some complex, important cases which attract the widespread attention of society, the people's jury should be applied.

Secondly, it is inevitable to construct so-called hearing procedures about sentences, namely, the courts should organize hearing procedures for the complex, important cases in which the result of the decision about the punishment is a bit more controversial. This hearing procedure would enable judges to collect the public opinions about the sentencing problems.

\section{SUMMARY}

In my essay I tried to highlight the fact that Chinese criminal procedure faces some serious problems concerning the sentencing system. Judges often fail in providing acceptable reasons and arguments to support their decisions on punishments. Judicial decisions are influenced by many internal and external factors and judges do not pay attention to making their decisions on sentences according to a coherent and consistent system of values. Their sentencing practice leads to an unpredictable, disproportional and unjust punishing system. The failure to provide rational reasons for particular sentences in judicial decisions is able to undermine the justice of the decisions and provides the opportunity for the public and the legal community to call the rightfulness of the decision into question. To avoid this kind of unjust sentencing system judicial practice needs to be reformed in some ways. Improving the quality of judicial reasoning on sentencing includes the need to reform the appointment system of judges, constructing an effective communication channel between the judges and society and developing judicial skills by setting up an effective training system. These reforms in the judicial system would contribute to creating a more just and predictable sentencing practice in China. 


\section{LITERATURE}

Frank, J., Law and the Modern Mind (Anchor Books 1963).

Ghestin, J. and Goubeaux, G., Traite De Droit Civil: Introduction General (Law Press 2004).

Rong, L., Research on the Guaranteeing System of Sentencing Justly (Minzu University of China Press 2013).

Stith, K. and Cabranes, J. A., Fear of Judging. Sentencing Guidelines in Federal Courts (University of Chicago Press 1998). 